\title{
Leibniz e o aperfeiçoamento da medicina: introdução ao texto e tradução
}

\author{
Leibniz and the perfecting of medicine: introduction to text and translation
}

\section{Arthur Leandro da Silva Marinho*}

Resumo: Neste artigo apresentamos uma tradução e discussão de uma carta do filósofo Leibniz (1646-1716), na qual ele discute ações para o aperfeiçoamento da medicina. A importância e atualidade desta carta consiste em propor ações públicas de controle de epidemias pelo estado, como também, discute o uso de medicação pela medicina para controle das epidemias. No primeiro momento, explicamos a importância da publicação desta carta, destinada a Germain Brice, no Journal des Savants. No segundo momento apresentamos a tradução do texto, onde ele sugere a coleta de informações para ajudar na contenção da disseminação das doenças epidemiológicas. Essa é uma sugestão da qual alguns governos modernos poderiam se beneficiar. No mesmo texto, Leibniz também faz referência ao tratamento de uma pandemia com uma substância considerada estranha.

Palavras-chave: Leibniz; Medicina; Modernidade

\begin{abstract}
In this article we present a translation and discussion of a letter by the philosopher Leibniz (1646-1716), in which he discusses actions for the improvement of medicine. The importance and timeliness of this letter consists of proposing public actions to control epidemics by the state, as well as discussing the use of medication by medicine to control epidemics. At first, we explained the importance of publishing this letter, addressed to Germain Brice, in the Journal des Savants. In the second moment, we present the translation of the text, where it calls for the collection of information to help contain the spread of epidemiological diseases, this is a suggestion that some modern governments could benefit from. In the same text, Leibniz also refers to the treatment of a pandemic with a substance considered foreign.
\end{abstract}

Keywords: Leibniz; Medicine; Modernity

\section{Introdução}

Neste artigo tratamos o desenvolvimento da medicina e o enfrentamento das pandemias no momento em que essas apareceram na história da filosofia moderna. Para tal finalidade, traduzimos uma carta de Leibniz (publicada em 1694) que acompanhou as mudanças pelas quais a medicina passou no século XVII. Por meio do texto filosófico, aqui traduzido, notamos que Leibniz foi um filósofo comprometido com seu tempo e com os avanços da medicina através de métodos que na época eram considerados atuais no combate das pandemias.

O filósofo alemão Gottfried Wilhelm Leibniz nos convida a pensar a modernidade, o que demanda de nós uma volta ao passado com o intuito de melhor compreender o presente. Nesse sentido, pensar as pandemias do passado e o modo como foram enfrentadas possibilita pensar ações voltadas para o tratamento das pandemias no presente. 0 filósofo alemão acredita que o futuro já é uma realidade presente. Pensar ações voltadas para o tratamento das pandemias que a cura ainda é desconhecida proporciona uma imersão na nossa realidade imediata. Segundo Leibniz, "como todo o estado presente de uma substância simples é naturalmente uma consequência do seu estado precedente, de tal maneira que o presente está 
aí grávido do futuro"1. Todo o futuro já é uma realidade presente, o futuro pós pandemia que se pretende atingir depende das atividades concretas no presente momento. Daí se pode concluir que no sistema filosófico leibniziano a constituição do indivíduo ocorre de forma histórica, através da relação de causa e efeito nas ações humanas. 0 presente grávido do futuro demonstra que as coisas no universo inteiro estão todas em conexão, portanto, o aperfeiçoamento da medicina aponta uma racionalidade que ordena e organiza continuamente o universo.

0 texto do filósofo Leibniz, extrato de uma carta aqui traduzido para língua portuguesa, evidencia as discussões a respeito do desenvolvimento da medicina na modernidade e sua consequente repercussão na atualidade. Trata-se de uma carta destinada ao historiador Germain Brice, publicada no Journal de Savants, em 1694, p. 338-340.

A partir de 1690, Leibniz compreendeu que os periódicos científicos eram importantes instrumentos de discussão filosófica, assim, Leibniz acompanhou o intenso movimento de fortalecimentos dos periódicos científicos no século XVII com intuito de ampliar a repercussão de suas ideias. Desse modo, quando Leibniz começa a escrever em periódicos,

[...] ele parece ter imaginado seus leitores em potencial, como seus correspondentes, como pessoas cuja formação deveria influenciar a maneira como ele apresentava suas ideias. Assim, como ele disse a um correspondente, ele usou a linguagem escolástica até certo ponto ao escrever para o periódico Acta de Leipzig e se acomodou mais ao "estilo dos cartesianos" ao escrever para outros, como o Journal des Savants ${ }^{2}$.

Assim, quando Leibniz publicou a supracitada carta, destinada a Germain Brice, no periódico Journal des Savants, ele teve em mente o alcance de toda a comunidade de potenciais leitores que este periódico alcançava, ou seja, seu interlocutor não era apenas Germain Brice. 0 arcabouço vocabular acompanhava as mudanças nas quais a ciência se caracteriza na modernidade. Por isso, sua linguagem acomodou-se às novidades do método cartesiano, com características marcadamente racionais e rigor metódico do pensamento. É um documento curto, contudo, é importantíssimo para que possamos compreender o filósofo e seu engajamento com os assuntos de sua época. Leibniz buscou instrumentalizar e organizar ações para enfrentar os desafios de seu tempo tendo em vista uma mudança para melhor no futuro.

Germain Brice foi um historiador parisiense que se diferenciou dos antecessores por propor uma visão moderna da sua cidade. A forma dele contar a história da cidade de Paris ganhou notoriedade por se configurar como guia prático para viajantes. Com isso, os seus textos constituíram um importante itinerário para conhecer não apenas as riquezas arquitetônicas, como também, artísticas de Paris.

Mesmo depois de deixar Paris, em 1676, Leibniz mantinha-se informado sobre os acontecimentos na cidade. Aliás, "Leibniz costumava pensar em voltar a Paris e até conspirou com Foucher para se tornar um membro correspondente da Académie des Sciences para que ele pudesse fazer visitas regulares, mas nada aconteceu conforme seus planos" 3 . Os textos de Germain Brice eram conhecidos na Paris do século XVII e atraía leitores pela metodologia criativa ao descrever a cidade. Seu método demonstrava profundo conhecimento das belezas das artes e da vida parisiense, minuciosamente retratadas em seu guia. Sua abordagem foi um sucesso e se tornou muito popular em Paris nos séculos XVII e XVIII.

Durante o período entre 1672 e 1676, Leibniz viveu em Paris em uma missão diplomática. Esse período é reconhecido com fundamental para seu desenvolvimento intelectual, pois,

\footnotetext{
${ }^{1}$ LEIBNIZ, Monadologia, p. 45.

2 BROWN \& FOX, Historical dictionary of Leibniz's philosophy, p. 131.

${ }^{3}$ BROWN \& FOX, Historical dictionary of Leibniz's philosophy, p. 177.
} 
[...] durante sua estadia, ele conheceu e foi influenciado por um grande número de matemáticos, cientistas e filósofos, incluindo Simon Foucher, Christiaan Huygens e Nicolas Malebranche. Leibniz avançou seu conhecimento em matemática e física e produziu alguns de seus importantes trabalhos sobre o cálculo infinitesimal 4

Os contatos que Leibniz travou nesse período com inúmeras personalidades políticas e com conhecidos nomes das ciências matemáticas e filosóficas refletiram nas suas produções intelectuais. Seus textos filosóficos após essa época mudam de forma radical. Foi após essa estadia em Paris que Leibniz escreveu para Brice. Em virtude da relevância científica do seu conteúdo, Leibniz decidiu publicar essas cartas posteriormente na revista científica Journal des savants. Nelas o Filósofo trata a importância da organização de um levantamento dos registros das pessoas que eram batizadas (ou seja, registro de nascimento), como também das pessoas que morreriam, o que permitiria obter informações demográficas importantes. Isso significa que Leibniz estava atento aos problemas da vida urbana parisiense, além dos tratamentos sugerido para amenizar as pandemias, como também, ao aperfeiçoamento da medicina no cuidado com a vida das pessoas.

Destacamos que as correspondências filosóficas de Leibniz constituem um instrumente relevante para compreensão da sua filosofia, nessas correspondências o filósofo alemão demonstrava seus principais pensamentos filosóficos. As correspondências foram numerosas. 0 acervo de Leibniz conta com mais de 1.000 correspondências, das quais 100 abordam temas filosóficos. Muitas dessas correspondências constituem partes valiosas da filosofia leibniziana. Assim,

[...] durante a vida de Leibniz, os periódicos se tornaram um importante instrumento de comunicação entre cientistas, filósofos e homens de letras em geral. 0 primeiro, o Journal des Savants, foi fundado em Paris em 1665 e o próprio Leibniz ajudou a fundar o Acta Eruditorum em Leipzig em 1682.

Entre as outras principais revistas da época que continham discussões sobre a filosofia de Leibniz e nas quais ele contribuiu estavam as Nouvelles de la République des Lettres de Amsterdã (fundada em 1684) e sua sucessora, a Histoire des Ouvrages des Savants de Rotterdã (fundada em 1684 ), bem como a jesuíta Mémoires pour l'Histoire des Sciences and des Beaux Arts de Trévoux (fundada em 1701). Leibniz também contribuiu para as transações da Royal Society 5 .

A comunicação por cartas era muito comum entre as pessoas e muitas delas tratavam de temas filosóficos com profundidade, depois esses temas passaram a ser publicados em periódicos científicos. Assim, a importância das correspondências de Leibniz se dá por conter as primeiras partes dos seus trabalhos científicos publicados em periódicos científicos e, muitas vezes, não só dão sentido aos seus tratados filosóficos, como também, dos trabalhos de outras pessoas com quem se correspondia. Contudo,

[...] quase todas as cartas que Leibniz escreveu permaneceram não lidas por quase ninguém, exceto a pessoa a quem foram direcionadas até que se tornassem objeto de interesse acadêmico. Elas mostram a alta prioridade dada por Leibniz a essa atividade e os problemas dos quais ele estava preparado para explicar suas ideias a outras pessoas ${ }^{6}$.

Decidimos traduzir essa carta com interesse em discutir a relação entre pandemia e filosofia na perspectiva leibniziana. Na carta de Leibniz, o cuidado com a saúde manifestado

\footnotetext{
${ }^{4}$ BROWN \& FOX, Historical dictionary of Leibniz's philosophy, p. 177.

${ }^{5}$ BROWN \& FOX, Historical dictionary of Leibniz's philosophy, p. 130-131.

${ }^{6}$ BROWN \& FOX, Historical dictionary of Leibniz's philosophy, p. 60.
} 
pelo interesse do levantamento anual de dados para medicina indica uma preocupação com o planejamento e melhoria da saúde, além do conhecimento do corpo humano. A carta que aqui traduzimos não é um tratado de filosofia, contudo, está repleta de questões e temas próprios da filosofia. Nesse sentido, as correspondências de Leibniz publicadas nas diversas revistas científicas têm a finalidade de expor os argumentos pertinentes à comunidade filosófica, logo, a publicação de Leibniz no Journal des Savants caracteriza a circulação das ideias e observações de projetos sanitários e de controle epidemiológicos necessários ao serviço de cuidados humanos.

O Journal des savants foi o mais conhecido e mais antigo periódico literário e científico em circulação da Europa, fundado por Denis de Sallo em 1665. Cartas publicadas nos periódicos científicos continham discussões de temas relevantes a ciência. As cartas traziam conteúdos descobertas atuais e urgentes da época e seus conteúdos eram contados de forma breve. Os temas acompanhavam os acontecimentos imediatos do contexto sócio-histórico e filosófico. Por isso, a carta de Leibniz que traduzimos aqui representa uma discussão em circulação na comunidade científica e apresenta observações na área de medicina cujo interesse científico era urgente.

Esse importante periódico francês tinha a finalidade de contribuir para o progresso da ciência, era um instrumento de rápida circulação com as novas pesquisas e discussão de interesse da comunidade científica no século XVII e subsequentes. O objetivo do Journal des Savants era refletir os interesses do público letrado da sociedade parisiense. Com publicação semanal, continha resenhas, obituários, relatórios de experimentos e observações científicas e artigos científicos. Através do Journal des Savants Leibniz se correspondia com seus interlocutores, que podiam responder no próprio periódico. Assim, o jornal era o principal instrumento de discussão e debate filosófico. Esse periódico foi um instrumento importante de circulação das ideias filosóficas na modernidade e, especificamente, para divulgar a filosofia de Leibniz:

A primeira apresentação pública de Leibniz de sua filosofia - seu Novo Sistema - apareceu em duas edições sucessivas do Journal des Savants em 1695.0 Journal também continha a resposta crítica de Foucher e a resposta de Leibniz, mas, naquele momento, Foucher morreu e as discussões sobre o Novo Sistema de Leibniz passaram para outros periódicos ${ }^{7}$.

0 texto que aqui traduzimos é importante para compreender as mudanças pelas quais o século XVII passou, principalmente, na área da medicina. Com isso, Leibniz aproxima a medicina das ciências da natureza. 0 termo natureza, na concepção leibniziana, diz respeito ao corpo vivo, ou seja, a corporeidade. A estrutura originária da individualidade na concepção leibniziana acentua o caráter espontâneo dos organismos da natureza. 0 corpo, na concepção leibniziana, não é uma máquina, mas sim uma elaboração complexa da organização da matéria, em outros termos, os fenômenos vitais não podem ser reduzidos na compreensão mecânica.

No tempo que Leibniz esteve em Paris, tomou conhecimento dos registros de batismos e funerais que foram importantes para que pessoas capacitadas tivessem importantes observações. Do mesmo modo, Leibniz tem conhecimento de prática sanitária semelhante que acontecia em Londres. A coleta de informações sobre doenças para ajudar a conter sua disseminação foi uma sugestão da qual alguns governos modernos puderam se beneficiar. Além disso, Leibniz acredita que havia outras medidas mais eficientes como a organização do planejamento anual dos acontecimentos relevantes da medicina. Inclusive, relatou as primeiras medidas do planejamento e como esses foram eficientes. 0 filósofo sugeriu que esse planejamento deveria ser estendido a outras cidades além de Paris. Nesse sentido, Leibniz fez

${ }^{7}$ BROWN \& FOX, Historical dictionary of Leibniz's philosophy, p. 130. 
algumas observações sobre o planejamento de Ramazzini, principalmente, sobre a saúde dos corpos humanos.

A respeito dos corpos humanos, Leibniz afirmou que as doenças epidêmicas e seus sintomas criavam variações na forma das pessoas viverem. Nessa carta, ele faz referência ao tratamento antimalárico que acontecia de forma pouco convencional por meio do uso da quinquina. Da mesma forma, argumentou que nem sempre o tratamento médico e científico com o uso da quinquina obteve sucesso. Isso evidenciava para ele que o uso desse medicamento, na época, carecia de observação e experimentação médica e científica. A quinquina era originária da América do Sul. No Peru os povos originários usavam a cortiça da quinquina no tratamento antimalárico. Isso é muito interessante, tendo em vista que nos faz pensar, por analogia, a respeito de uso de substâncias ou medicamentos que ainda carecem de estudos farmacológicos e experimentação, como a recente discussão e sugestão do uso da cloroquina no tratamento experimental contra o Coronavírus da síndrome respiratória aguda grave 2. Coincidentemente, a substância cloroquina é usada atualmente no tratamento da malária. Por fim, Leibniz aponta que a atuação e autoridade do governante e a atuação dos agentes públicos são fundamentais na atenção e cuidado da alma e do corpo enquanto ação contra as pandemias.

\title{
No caminho do aperfeiçoamento da medicina ${ }^{8 ; 9}$
}

\author{
Um extrato de uma carta de Leibniz ${ }^{10}$
}

[JS p. 338-340]11

Eu não sei se em Paris ainda se continua com os registros ou listas de batismos e funerais desta cidade grande que eram compiladas no tempo em que eu lá estava. Esse projeto pareceu muito útil, assim como os Bills of Mortality em Londres, dos quais pessoas capacitadas extraíram importantes observações. No entanto, poderíamos ir mais longe, elaborando uma história anual da medicina para Paris e a Ilha de França, bem como para outras províncias, sobre o plano que o Sr. Ramazzini ${ }^{12}$ nos deu, ele é o médico capacitado do duque de Modena, com quem eu me encontrei quando estava naquele país. $\mathrm{Eu}$ insisti fortemente que ele executasse e seguisse esse projeto tão louvável. Ele enfim se pôs a fazê-lo, e já havia nos dado alguns anos, tendo até me concedido a honra de dedicar o segundo a mim. Eu os tenho

\footnotetext{
8 Nossa tradução foi feita a partir do texto original no Journal des Savants, 1964, p. 338-340. Disponível em: https://gallica.bnf.fr/ark:/12148/bpt6k56541d/f368.image. Acessado em 15 de abril de 2020 às 15h10min. Também consultamos e levamos em consideração uma tradução do disponível do texto em inglês, intitulado: On the way of perfecting medicine, traduzido por Lloyd Strickland. Disponível: http://www.leibniztranslations.com/medicine.htm. Acessado em 15 de abril de 2020 às $15 \mathrm{~h}$.

${ }_{9}$ Agradeço ao amigo e professor na Universidade Metropolitana de Manchester (MMU), Lloyd Strickland por autorizar que utilizasse o seu texto para basear nossa tradução em Língua Portuguesa. Agradeço a amiga e professora na Universidade Estadual da Paraíba (UEPB), Eugênia Ribeira Teles que leu e deu sugestões úteis. Usufrui também dos comentários detalhados do parecerista deste artigo, a quem também gostaria de expressão minha gratidão.

${ }^{10}$ Esse texto é um extrato da carta de Leibniz a Germain Brice, publicada em 26 de julho de 1964 no Journal des Savants.

11 Leibniz, Journal des Savants , p. 338-340.

Disponível em: https://gallica.bnf.fr/ark:/12148/bpt6k56541d/f368.image. Acessado em 15 de abril de 2020 às $15 \mathrm{~h} 10 \mathrm{~min}$.

12 Bernardino Ramazzini (1633-1714), médico e professor de Teoria da Medicina na Universidade de Modena de 1682 a 1700.
} 
inseridos nas coleções ou efemérides que nossos médicos alemães, que se dizem "curiosos sobre a natureza", publicaram por muito tempo todos os anos. Todavia, eu não tenho nenhuma dúvida de que na França é possível melhorar consideravelmente esses inícios. Este médico falou primeiro sobre as estações do ano e a constituição do ar que foi observada ao longo do ano na região cuja história médica ele se comprometeu a fornecer, a saber, da cidade de Modena e da vizinha Lombardia. Depois disso, ele relata como os grãos e frutas prosperaram ali e as doenças que prevaleciam entre os animais, e tudo isso em poucas palavras. A partir daí, ele chega à questão principal, que é a saúde dos corpos humanos, na qual observa não apenas doenças epidêmicas e seus sintomas, mas também como outras doenças mudaram, pois é certo que há grandes variações de acordo com as constituições dos tempos. Acima de tudo, ele observa quais medicamentos tiveram o melhor efeito, e o que é chamado nocentia [que coisas prejudicam] e juvantia [que coisas ajudam]: e nos dois anos que eu já recebi dele, ele observou [JS p. 339] grandes variações e, como foram mudanças do preto para o branco; entre outros, com relação à quinquina ${ }^{13}$, que obteve sucesso incomparavelmente melhor em um ano do que no outro. E não deve haver dúvida de que anos semelhantes aos anteriores muitas vezes retornam, onde o passado seria de maior utilidade para decidir sobre este assunto no futuro, enquanto agora estamos reduzidos a aprender quase sempre do zero às custas dos doentes.

É fácil julgar que tesouro de observações poderíamos ter se algo semelhante tivesse sido feito há algum tempo. Mas é sempre hora de começar as coisas boas; estas coisas boas devem ser feitas em várias províncias, e até por ordem pública, sendo um ponto importante da polícia, ainda mais digno de ser executado, pois só precisa ser desejado e exige quase nenhum problema ou despesa. E como a polícia é excelente na França, esses tipos de projetos podem ser executados lá melhor do que em outros lugares.

Não seria necessário que livros inteiros fossem escritos em todos os lugares, como foi iniciado em Modena. Uma carta de poucas páginas escrita por um médico capacitado, sobre sua cidade ou província, seria suficiente, dirigindo-a, por exemplo, ao Primeiro Doutor do $\mathrm{Re}^{14}$, que sob sua autoridade receberia uma coleção delas todos os anos. É verdade que o projeto merece ser expandido ainda mais nas grandes cidades e, especialmente, na capital do reino, e imagino que o tenente de polícia ficaria encantado em ajudá-lo e encorajar aqueles que gostariam de empreendê-lo. A França, ao dar um bom exemplo de precisão e curiosidade, prestaria um serviço muito considerável à raça humana, o que não seria indigno do glorioso reinado do monarca que atualmente a governa ${ }^{15}$. Os Mithridates ${ }^{16}$, os Jubas ${ }^{17}$ e os Gentius ${ }^{18}$, a quem somos devedores por terem nos concedido alguns remédios, não teriam feito nada comparável ao que seria devido à Sua Majestade se ele tomasse em conta o fato e a causa da medicina, como ele fez em relação à astronomia com um sucesso ao qual os esforços dos Alfonsos $^{19}$, Ulugh-Begs ${ }^{20}$, e outros reis semelhantes [JS p340] não poderiam ser comparados.

\footnotetext{
13 Casca seca de árvores de Cinchona, usada no tratamento da malária. Ramazzini foi um dos primeiros a promover seu uso.

14 Na França, o Primeiro Doutor do Rei era o chefe de todos os oficiais de saúde a serviço do monarca e responsável pela organização da medicina em todo o reino. Na época em que Leibniz escreveu, o cargo era de Guy-Crescent Fagon (1638-1718).

15 Uma referência a Luís XIV da França.

16 Mitrídates VI VI (135-63 a.C.) foi durante grande parte de sua vida rei de Ponto e Armênia Menor, um formidável inimigo de Roma. Em sua juventude, ele tinha a reputado ter desenvolvido imunização a vários venenos que tinha conhecimento, tomava doses crescentes de veneno até que o organismo fosse capaz de tolerar
} uma dose mortal.

17 Juba II (52 a.C.-23 d.C.), rei berbere da Numídia e de Cesareia (Mauritânia romana), tem a reputação de ter reconhecido e descrito os poderes curativos da eufórbia. Juba II teria feito chegar esta planta ao seu físico (ou médico) Euphorbos, para serem exploradas as suas capacidades curativas e laxativas, no século I antes de Cristo.

18 Diz-se que Gêncio, último rei dos Ardiaei que governou entre 181-168 aC., descobriu as propriedades tônicas da família de plantas Gentiana, desde o seu nome.

${ }^{19}$ Alfonso X (1221-1284) foi rei de Castela, Leão e Galiza e conhecido por seu interesse e incentivo à astronomia. 
Certamente, os homens precisam de uma autoridade tão grande quanto a dele para voltarem ao verdadeiro caminho; aqueles que extravagam sempre fora de si mesmos negligenciam-se por uma cegueira que parece fatal e que merece mais suas atenções. E pode-se dizer que é uma verdade tão certa quanto lamentável que a alma e o corpo sejam as primeiras coisas que devem ser pensadas e as últimas coisas que são pensadas.

\section{Referências}

LEIBNIZ. Extrato de uma carta do Sr. Leibniz. Paris: Journal de , 1694, p. 338-340. Disponível: https://gallica.bnf.fr/ark:/12148/bpt6k56541d/f368.image. Acesso: 15 de abril de 2020 as 15h10min.

LEIBNIZ. Monadologia. Tradução e apresentação: Adelino Cardoso. Lisboa: Edições Colibri, 2016.

LEIBNIZ. On the way of perfecting medicine. Organização, tradução e notas: Lloyd Strickland. Edição digital. Disponível: http://www.leibniz-translations.com/medicine.htm. Acesso: 15 de abril de 2020 às $15 \mathrm{~h}$.

BROWN, Stuart. \& FOX, N. J. Historical Dictionary of Leibniz's Philosophy: Estados Unidos: Scarecrow press, 2006.

${ }^{20}$ Ulugh Beg (1394-1449) era um sultão do Império Timúrida, conhecido por seu trabalho como astrônomo e matemático. 